\title{
A systematic review and meta-analysis on intraocular lens implantation with different performances for the treatment of cataract
}

\author{
Qihong Chi ${ }^{1}$, Tao Yang $^{2}$, Yang Chen ${ }^{3}$ \\ ${ }^{1}$ Department of Ophthalmology, Wenling Hospital Affiliated to Wenzhou Medical University, Wenling, China; ${ }^{2}$ Department of Ophthalmology, \\ Taizhou Hospital of Zhejiang Province affiliated to Wenzhou Medical University, Taizhou, China; ${ }^{3}$ Department of Ophthalmology, Taizhou First \\ People's Hospital, Taizhou, China \\ Contributions: (I) Conception and design: Q Chi; (II) Administrative support: T Yang; (III) Provision of study materials or patients: Q Chi, Y Chen; \\ (IV) Collection and assembly of data: All authors; (V) Data analysis and interpretation: All authors; (VI) Manuscript writing: All authors; (VII) Final \\ approval of manuscript: All authors. \\ Correspondence to: Yang Chen. No. 218 Hengjie Road, Huangyan District, Taizhou, China. Email: chenyangcy033@163.com.
}

\begin{abstract}
Background Cataract is one of the common eye diseases. At present, Phacoemulsification combined with traditional intraocular lens (IOL) implantation can achieve satisfactory rejuvenation effects. However, the correction of corneal astigmatism is limited, while Toric IOL implantation can provide good astigmatism correction treatment.

Methods: We retrieved randomized controlled trials (RCTs) on the treatment of cataracts published in the PubMed, EBSCO, MEDLINE, EMBASE, Science Direct, Cochrane Library, China National Knowledge Infrastructure (CNKI), Wanfang, and Weipu databases. Professional journals were searched manually to avoid omissions. The research subject search terms included cataract, astigmatism, IOL, and intraocular lens. The observation indicators search terms included uncorrected distance visual acuity (UDVA), best-corrected distance visual acuity (BDVA), residual corneal astigmatism, and cataract cure rate.
\end{abstract}

Results: A total of 12 articles were included. The articles were tested for heterogeneity of UDVA measured using the Logarithm of Mininal Angle Resolution (LogMAR) visual acuity chart, and the results showed that Chi-squared test $\left(\mathrm{Chi}^{2}\right)=75.21$, degree of freedom $(\mathrm{df})=11$, and $\mathrm{I}^{2}=85 \%>50 \%$, so the random effects model (REM) was adopted for analysis. The results indicated that the differences between the Toric and Non-Toric IOL groups statistically significant, and the Toric IOL group had a significant therapeutic effect $[Z=2.18$, mean difference $(\mathrm{MD})=-0.05,95 \%$ confidential interval $(\mathrm{CI}):-0.09,-0.00, \mathrm{P}=0.03]$. The fixed effects model (FEM) was adopted to analyze the determination of BDVA by LogMAR visual acuity chart in 6 articles. The results suggested that the difference between the Toric IOL and non-Toric IOL groups was not statistically significant $(\mathrm{Z}=0.29, \mathrm{MD}=-0.00,95 \% \mathrm{CI}:-0.02,0.01, \mathrm{P}=0.77)$. Heterogeneity analysis was performed on three articles in terms of residual corneal astigmatism, which showed that $\mathrm{Chi}^{2}=75.55, \mathrm{df}=3, \mathrm{I}^{2}=96 \%>50 \%$, and $\mathrm{P}<0.00001$. The REM analysis results revealed that the difference between the two groups was not statistically significant, and the Toric IOL group had low residual corneal astigmatism $(\mathrm{Z}=1.35, \mathrm{MD}=-0.34$, 95\% CI: $-0.83,0.15, \mathrm{P}=0.18)$.

Discussion: The meta-analysis results confirmed that Toric IOL implantation showed obvious advantages in improving UDVA and corneal residual astigmatism in cataract patients.

Keywords: Astigmatism; intraocular lens (IOL); cataract; curative effect; meta-analysis

Submitted Nov 25, 2021. Accepted for publication Jan 14, 2022.

doi: $10.21037 /$ apm-21-3767

View this article at: https://dx.doi.org/10.21037/apm-21-3767 


\section{Introduction}

Cataract is a decrease in vision caused by a reduction in the transparency of the lens or a change in color (1). Cataract patients will feel blurred vision at first, like smoke blocking their eyes, with the vision loss becoming more obvious the longer the course of the disease. Senile cataract is the most common type of cataract, and its incidence gradually increases with age. Some elderly people often suffer from falls, fractures, and other serious accidents due to unclear vision (2-4). Without treatment, vision will gradually deteriorate, which can eventually lead to blindness, and seriously affect the patient's visual quality and quality of life.

Traditional intraocular lens (IOL) implantation for the treatment of cataract can achieve an ideal rejuvenation effect, but its corrective effect on corneal astigmatism has certain defects (5). With the improvement of living standards, the requirements of doctors and cataract patients on the level of vision recovery after surgery have also increased. Mendicute et al. [2008] (6) proposed that traditional IOL implantation combined with transparent keratotomy or peripheral limbal lysis can improve astigmatism, but the operation surgical process is complicated, the maximum correction degree is limited, and it is easy to cause keratitis. Blue-light filtering intraocular lens is made of special materials, which is closer to the spectrum of human lens. It can filter ultraviolet and blue light harmful to eyes at the same time and protect retina. The foldable intraocular lens is made of foldable and flexible soft material, which can be folded and implanted in cataract surgery. The incision is less than $3 \mathrm{~mm}$, with less surgical damage, less postoperative reaction, quick recovery, good stability in intraocular position, low incidence of after-cataract and UV protection. However, there is some astigmatism after operation, and the incidence of posterior capsule opacification in the long term is relatively high, which is suitable for cataract patients in general population. The emergence of a new Toric IOL provides conditions for cataract surgery to treat astigmatism at the same time (7-9). The principle of Toric IOL is to superimpose a cylindrical lens of appropriate power in the direction of the maximum refractive power of the cornea to correct astigmatism (10). In recent years, there have been many reports at home and abroad comparing the clinical efficacy of Toric IOL implantation and traditional IOL implantation in the treatment of cataract. However, inconsistent findings have been reported as to whether Toric IOL implantation can improve the vision of cataract patients and correct astigmatism.
Systematic evaluation and meta-analysis are the most commonly used research methods in evidence-based medicine, the best source of scientific evidence, and the most frequently used tools in clinical medicine. Systematic reviews and meta-analysis are usually used interchangeably, with the same purpose and meaning (11). Meta-analysis refers to the collection and analysis of multiple similar studies to increase the total sample size from a statistical point of view, so as to improve the effectiveness of the results. It can be used to comprehensively evaluate the results of similar studies that are inconsistent or those with no statistical differences, them to understand the actual situation (12). The rational use of meta-analysis can not only complete the collection of research, but also comprehensively use clinical practice and conclusions to promote the application of evidence-based medical research.

In this study, we performed a comprehensive literature retrieval of related research, and systematic evaluation and meta-analysis were adopted to objectively evaluate the differences in clinical efficacy between Toric IOL and traditional IOL in the treatment of cataract, so as to provide evidence-based references for the clinical diagnosis and treatment of cataract. We present the following article in accordance with the PRISMA reporting checklist (available at https://apm.amegroups.com/article/view/10.21037/apm$21-3767 / \mathrm{rc})$.

\section{Methods}

\section{Literature retrieval}

We performed a literature search of the PubMed, EBSCO, MEDLINE, EMBASE, Science Direct, Cochrane Library, China National Knowledge Infrastructure (CNKI), Wanfang, and China Science and Technology Journal Database to retrieve randomized controlled trials (RCTs) of Toric IOL implantation in the treatment of cataracts published from the establishment of the database to July 25, 2021. Professional journals were retrieved manually to avoid omissions.

The research objects search terms included cataract, astigmatism, intraocular lens, and intraocular lens. The observation indicators search terms included uncorrected distance visual acuity (UDVA), best-corrected distance visual acuity (BDVA), and residual corneal astigmatism.

The subject terms and free words were combined to conduct multiple searches to obtain articles that could be included, and the obtained articles were then tracked using 
the search engine. The relevant experts and researchers who published the articles were contacted to obtain the latest research progress. The Rev Man 5.3 software provided by the Cochrane Collaboration was used to evaluate the quality of the included articles.

\section{Literature inclusion and exclusion criteria}

Articles meeting the following requirements were eligible for inclusion in this study: (I) prospective randomized controlled trails (RCTs); (II) articles with cataract patients with corneal astigmatism as the research objects; (III) articles that mentioned phacoemulsification combined with Toric IOL implantation intervention in the treatment group; and (IV) articles that mentioned phacoemulsification combined with traditional IOL implantation intervention in the control group.

Articles meeting the following criteria were excluded: (I) cases studies, overviews, conferences, and reviews; (II) nonRCTs; (III) repeatedly published literature; (IV) articles with missing data and information, and those no original data; and (V) articles whose latest research results were unavailable.

\section{Clinical outcome indicators}

The clinical outcome indicators included UDVA, BDVA, and residual corneal astigmatism.

\section{Data extraction}

Two professionals were required to use a unified Microsoft Excel (Microsoft, USA) to independently conduct article screening and data extraction, as well as subsequent crosschecking. Disagreements between the two professionals were resolved through discussion. The main data extracted included general information (title, first author's name, country, published journal, publication period, etc.), basic information of the research objects (gender, age, sample size, etc.), specific operation and follow-up time of the intervention measures, and clinical efficacy outcome indicators: (UDVA, BDVA, and residual corneal astigmatism).

\section{Bias risk assessment}

Two professionals were required to strictly follow the five evaluation criteria of RCTs to repeatedly evaluate the risk of bias in the included articles. Differences between the experts were resolved through discussion. The evaluation criteria included the following aspects: whether the random method was correct; whether allocation concealment was strictly implemented; whether the blinding method was used; whether there was withdrawal or loss to followup; whether the number of patients in each group of each article was included, whether the ages of patients was comparable, whether there was a selection bias, and whether there was an influence of opportunity and its magnitude. All randomized patients were eliminated by the smallest and most reasonable method, and the acquired data were analyzed.

For included articles that fully satisfied the above five quality evaluation standards and employed correct methodology, the bias was least likely to affect the results, and were classified as Grade A. However, if one or more of the quality evaluation criteria in the included articles were only partly satisfied, the bias that occurred may have had a moderate impact on the results, and it was recorded as Grade B. Furthermore, if one or more quality evaluation criteria were not met at all in the included articles, and the resulting bias showed a high probability of affecting the results, then the possibility of bias in the study was high, which was recorded as Grade C.

\section{Statistical analysis}

The bias risk assessment chart under Rev Man 5.3 software (Cochrane, United States of America) was adopted to assess the risk bias of the included articles, sort the data, filter, and input the software to draw the chart. The odds ratio (OR) was used for counting data, and mean difference (MD) was used for measurement data. Each effect was represented by a $95 \%$ confidence interval (CI). The heterogeneity among the articles was explored using the $\mathrm{I}^{2}$ test. $\mathrm{P}>0.01$ and $\mathrm{I}^{2}<50 \%$ indicated that the heterogeneity of the included articles was small, and the fixed effects model (FEM) was used for meta-analysis. However, $\mathrm{P}<0.01$ and $\mathrm{I}^{2}>50 \%$ indicated that the included articles were heterogeneous, and the random effects model (REM) was used for metaanalysis.

\section{Sensitivity analysis}

The REM and the FEM were used to compare the results. According to the consistency of the results, the reliability of the combined results was analyzed, and a funnel chart was 


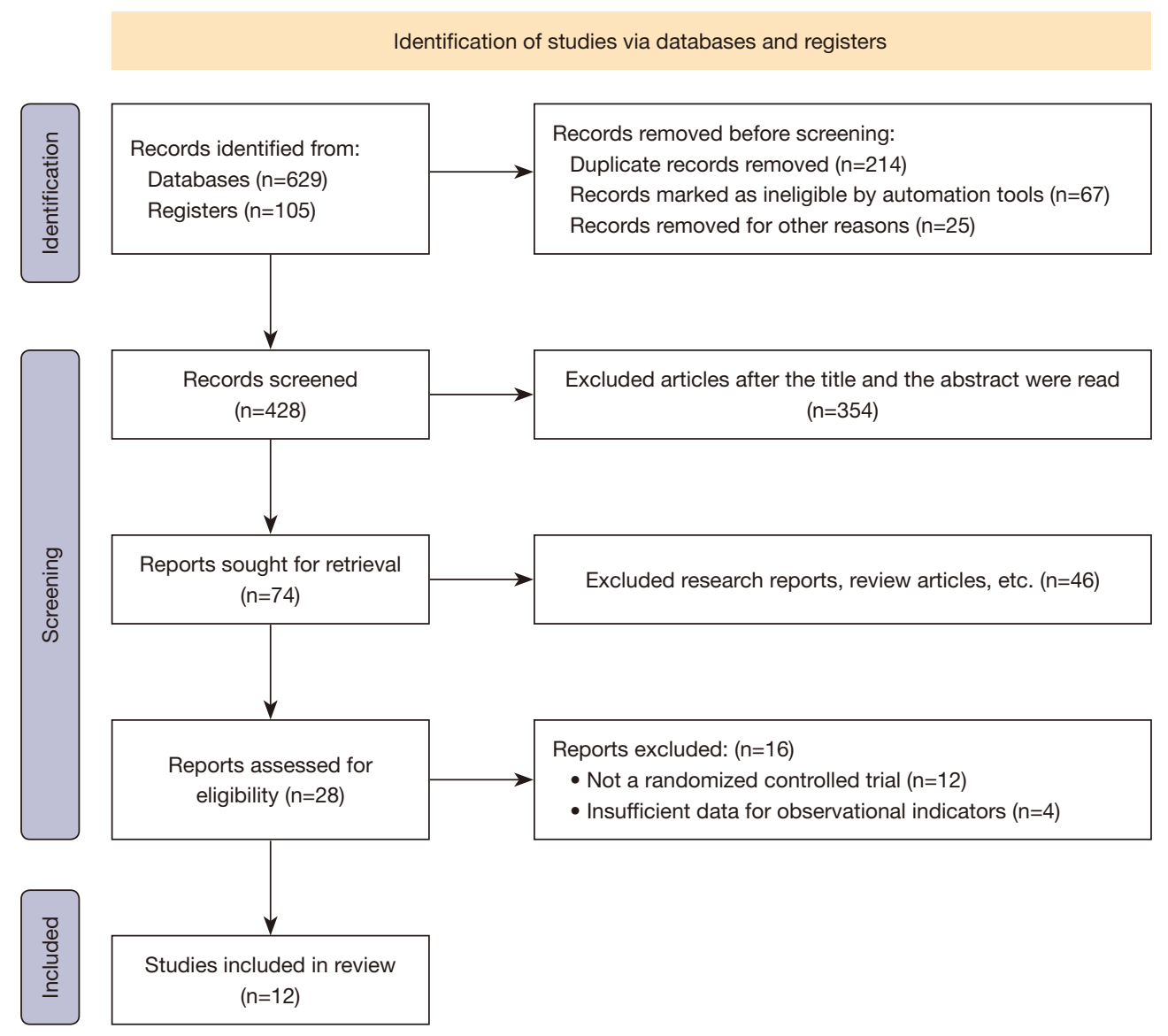

Figure 1 Literature retrieval flow chart.

used to determine whether there was publication bias.

\section{Results}

\section{Retrieval results and basic information of the included articles}

Six hundred twenty-nine documents were obtained by searching the database, 105 documents were obtained by manually searching journals, 214 documents that were repeatedly published, 67 documents that were unqualified, and 25 documents that were rejected by other reasons were excluded. The remaining 428 articles were selected by title selection. By reading abstracts and titles, 354 articles were deleted, leaving 74 articles. Excluding 46 research reports and reviews, there were 28 papers. After reading the full text, 12 articles of non-randomized controlled trials were excluded, and the related information of the research could not be further extracted. Four articles were excluded, and finally 12 articles were included in meta-analysis. Figure 1 is a flow chart of literature retrieval.

The quality evaluation results show that there are 9 papers with grade A (75\%), 2 papers with grade B $(16.67 \%)$ and 1 paper with grade C $(8.33 \%)$. Among the 12 articles that met the inclusion criteria, the sample size ranged from 24 to 517 cases. In 12 articles, nakedeye far vision, best corrected far vision, residual corneal astigmatism, cataract cure rate and follow-up time were described in detail. Table 1 is the basic characteristics of the included literature.

\section{Results of risk bias evaluation of the included articles}

Figure 2 shows the risk bias evaluation diagram of the included articles (drawn using Rev Man 5.3 software). Figure 3 is a summary chart of the risk bias of the included articles. Of the 12 articles in this study, 7 articles described the allocation concealment in detail, 3 article described the 
Table 1 Basic characteristics of included articles

\begin{tabular}{|c|c|c|c|c|c|c|c|c|c|c|}
\hline \multirow{2}{*}{ First author } & \multirow{2}{*}{$\begin{array}{c}\text { Year of } \\
\text { publication }\end{array}$} & \multicolumn{2}{|c|}{$\begin{array}{c}\text { Cases } \\
\text { (patient/eyes) }\end{array}$} & \multicolumn{2}{|c|}{ Age (years) } & \multicolumn{2}{|c|}{ Intervention } & \multicolumn{2}{|c|}{ Corneal divergence (D) } & \multirow{2}{*}{ - Follow-up time } \\
\hline & & $\begin{array}{l}\text { Toric } \\
\text { IOL }\end{array}$ & $\begin{array}{c}\text { Non-Toric } \\
\text { IOL }\end{array}$ & Toric IOL & $\begin{array}{c}\text { Non-Toric } \\
\text { IOL }\end{array}$ & Toric IOL & Non-Toric IOL & Toric IOL & $\begin{array}{c}\text { Non-Toric } \\
\text { IOL }\end{array}$ & \\
\hline Freitas (13) & 2014 & $15 / 30$ & $16 / 32$ & $65.67 \pm 6.28$ & $71.75 \pm 8.87$ & $\begin{array}{l}\text { Acrysof } \\
\text { Toric IOL }\end{array}$ & $\begin{array}{c}\text { Acrysof Natural } \\
\quad I O L+\mid R I\end{array}$ & $1.41 \pm 0.54$ & $1.32 \pm 0.47$ & $\begin{array}{c}1,3 \text { and } \\
6 \text { months after } \\
\text { operation }\end{array}$ \\
\hline $\begin{array}{l}\text { Hirnschall } \\
\text { (15) }\end{array}$ & 2014 & $30 / 30$ & $30 / 30$ & $71.0 \pm 8.4$ & $71.0 \pm 8.4$ & $\begin{array}{c}\text { Rayner } \\
\text { T-Flex } \\
\text { Toric IOL }\end{array}$ & $\begin{array}{c}\text { Rayner Non- } \\
\text { Toric IOL + } \\
\text { PCRI }\end{array}$ & $1.57 \pm 0.44$ & $1.70 \pm 1.42$ & $\begin{array}{c}\text { 1, } 6 \text { months } \\
\text { after operation }\end{array}$ \\
\hline $\begin{array}{l}\text { Liu Group A } \\
\text { (17) }\end{array}$ & 2014 & $15 / 15$ & $15 / 15$ & $72.17 \pm 9.55$ & $70.75 \pm 8.61$ & $\begin{array}{l}\text { Acrysof } \\
\text { Toric IOL }\end{array}$ & $\begin{array}{l}\text { Non-Toric } \\
\text { IOL+PCRI }\end{array}$ & $1.15 \pm 60.31$ & $1.17 \pm 0.28$ & $\begin{array}{c}1-6 \text { months } \\
\text { after operation }\end{array}$ \\
\hline Liu Group B & & $12 / 12$ & $12 / 12$ & $50-88$ & $49-87$ & $\begin{array}{l}\text { Acrysof } \\
\text { Toric IOL }\end{array}$ & $\begin{array}{l}\text { Non-Toric } \\
\text { IOL+PCRI }\end{array}$ & $2.08 \pm 0.24$ & $2.13 \pm 0.29$ & $\begin{array}{c}\text { 1-6 months } \\
\text { after operation }\end{array}$ \\
\hline Maedel (18) & 2014 & $18 / 18$ & $21 / 21$ & $70.1 \pm$ & \pm 11.8 & $\begin{array}{l}\text { Aspheric } \\
\text { Toric IOL }\end{array}$ & $\begin{array}{l}\text { Aspheric Non- } \\
\text { Toric IOL+OCCI }\end{array}$ & $1.69 \pm 0.41$ & $1.67 \pm 0.30$ & $\begin{array}{l}\text { At the 1st week, } \\
\text { 3rd and 9th } \\
\text { months after } \\
\text { operation. }\end{array}$ \\
\hline $\begin{array}{l}\text { Mendicute } \\
\text { (19) }\end{array}$ & 2009 & $20 / 20$ & $20 / 20$ & $69.3 \pm 8.2$ & $71.9 \pm 6.8$ & $\begin{array}{l}\text { Acrysof } \\
\text { Toric IOL }\end{array}$ & $\begin{array}{c}\text { Acrysof Non- } \\
\text { Toric IOL + } \\
\text { OCCl }\end{array}$ & $1.75 \pm 0.71$ & $1.66 \pm 0.63$ & $\begin{array}{c}3 \text { months after } \\
\text { operation }\end{array}$ \\
\hline Visser (22) & 2014 & $41 / 82$ & $45 / 90$ & $69.9 \pm 7.6$ & $71.3 \pm 9.1$ & $\begin{array}{l}\text { Acrysof } \\
\text { Toric IOL }\end{array}$ & $\begin{array}{c}\text { Acrysof Non- } \\
\text { Toric IOL }\end{array}$ & $2.02 \pm 0.95$ & $2.00 \pm 0.84$ & $\begin{array}{c}\text { Six months } \\
\text { after operation }\end{array}$ \\
\hline Waltz (23) & 2015 & $\begin{array}{c}102 \\
\text { cases }\end{array}$ & 95 cases & $67 \pm 10$ & $65 \pm 12$ & $\begin{array}{l}\text { Acrysof } \\
\text { Toric IOL }\end{array}$ & $\begin{array}{c}\text { TECNIS } \\
\text { 1-piece IOL }\end{array}$ & $1.07 \pm 0.28$ & $1.12 \pm 0.25$ & $\begin{array}{c}\text { Six months } \\
\text { after operation }\end{array}$ \\
\hline Zhang (24) & 2011 & $30 / 56$ & $30 / 54$ & $65.67 \pm 6.28$ & $71.75 \pm 8.87$ & $\begin{array}{l}\text { Acrysof } \\
\text { Toric IOL }\end{array}$ & $\begin{array}{c}\text { Acrysof } \\
\text { Spherical IOL }\end{array}$ & $1.33 \pm 0.50$ & $1.26 \pm 0.46$ & $\begin{array}{c}1,3 \text { and } \\
6 \text { months after } \\
\text { operation }\end{array}$ \\
\hline
\end{tabular}

IOL, intraocular lens; OCCI, opposite clear corneal incisions; PCRI, peripheral corneal relaxing incisions; AK, astigmatic keratotomy; LRI, limbal relaxing incisions. 


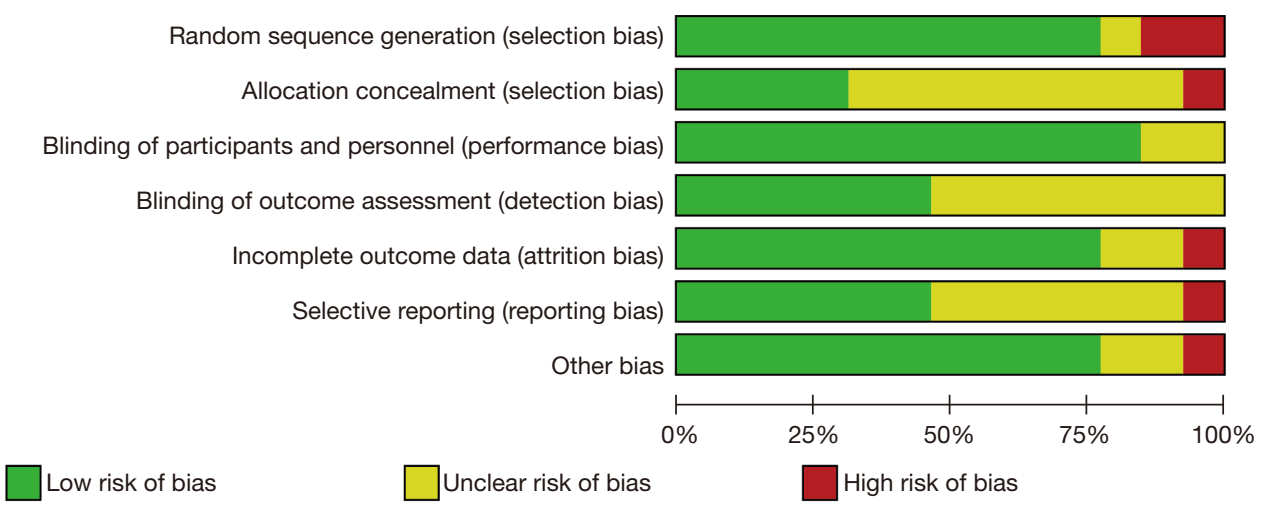

Figure 2 Risk bias evaluation of the included articles.

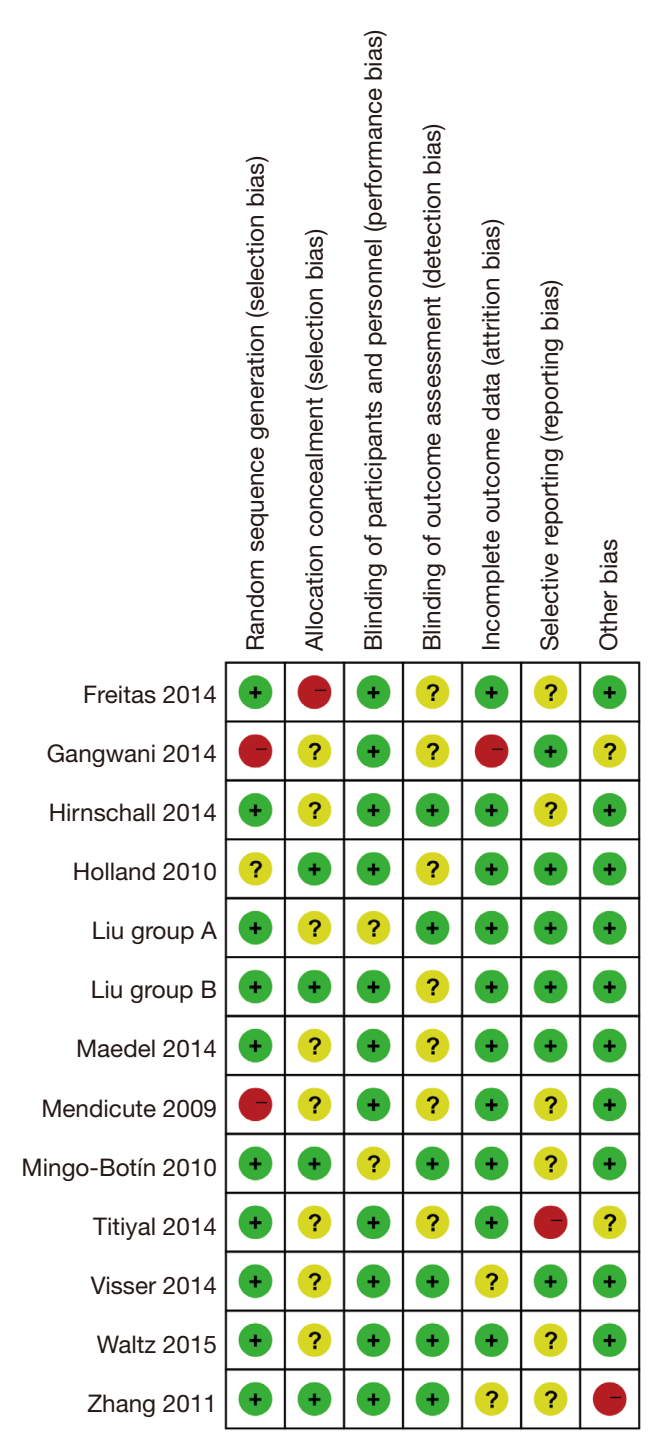

Figure 3 Summary diagram of risk bias evaluation of the included articles. “+”: low risk; “-”: high risk; "?”: not clear. correct random allocation methods, and 2 article did not use blinding.

\section{Meta-analysis results of LogMAR visual acuity chart to measure UDVA}

Twelve RCTs (13-24) analyzed the LogMAR visual acuity chart to determine the UDVA and its standard deviation. Figure 4 shows the forest plot of the UDVA measured by the LogMAR visual acuity chart. The six articles used continuous variables to describe the determination of UDVA by the LogMAR visual acuity chart. The overall heterogeneity test showed that $\mathrm{Chi}^{2}=75.21$, degree of freedom $(\mathrm{df})=11$, and $\mathrm{I}^{2}=85 \%>50 \%$, which indicated that there was heterogeneity among the articles. In most articles, the horizontal line of the $95 \%$ CI was to the left of the invalid vertical line. The REM analysis results revealed that the Toric IOL group was statistically significant compared with the non-Toric IOL group $(\mathrm{Z}=2.18, \mathrm{MD}=-0.05,95 \%$ CI: $-0.09,-0.00, P=0.03)$. Figure 5 displays the funnel chart of the LogMAR visual acuity chart to determine the UDVA. The circles included in the articles were concentrated in the midline attachment and were basically symmetrical to the midline, indicating that the accuracy of the included articles was high and there was no publication bias.

\section{Meta-analysis results of BDVA measured by LogMAR eye chart}

Six RCTs $(13,17,18,19,20,24)$ analyzed the LogMAR visual acuity chart to determine the BDVA. Figure 6 shows the forest plot of the BDVA determined by the LogMAR visual acuity chart. The three articles used continuous variables to 


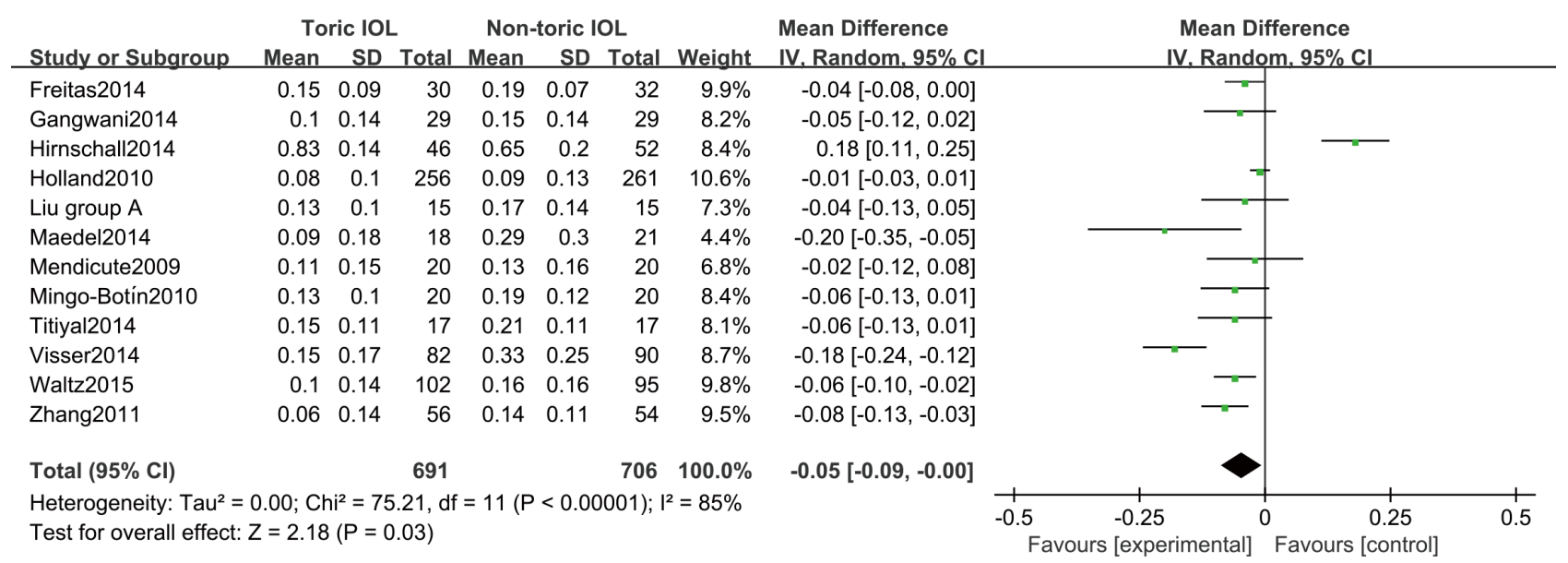

Figure 4 Forest plot of LogMAR visual acuity chart to determine the UDVA. CI, confidence interval; df, degree of freedom; IOL, intraocular lens. uncorrected distance visual acuity; UDVA, uncorrected distance visual acuity.

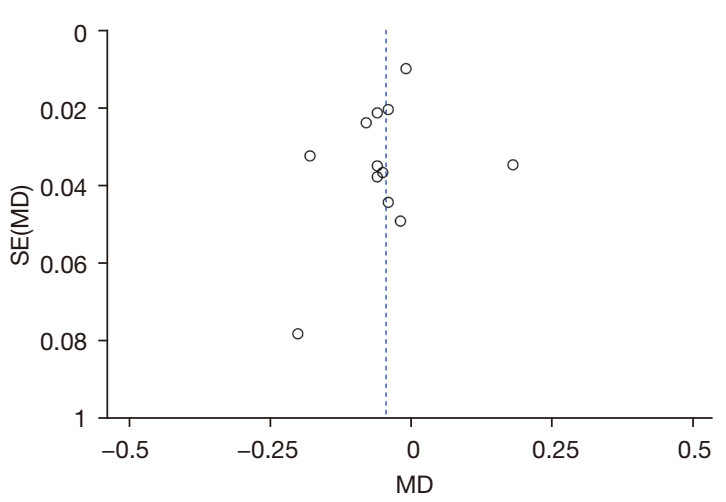

Figure 5 Funnel chart of UDVA measured by the LogMAR eye chart. MD, mean difference; SE, standard error; UDVA, uncorrected distance visual acuity.

describe the BDVA measured by the LogMAR visual acuity chart. There were 295 cases in total, including 145 cases in the Toric IOL group, and 150 cases in the non-Toric IOL group. The overall heterogeneity test showed $\mathrm{Chi}^{2}=2.95, \mathrm{df}$ $=6, \mathrm{I}^{2}=0 \%<50 \%$, and $\mathrm{P}=0.82$, which indicated that there was no heterogeneity among the included articles. The FEM analysis results indicated that the difference between the Toric IOL and non-Toric IOL groups was not statistically obvious $(Z=0.29, \mathrm{MD}=-0.00,95 \% \mathrm{CI}:-0.02,0.01$, $\mathrm{P}=0.77)$. Figure 7 displays the funnel chart of the LogMAR visual acuity chart to determine the BDVA. The circles included in the articles were concentrated in the midline attachment and were basically symmetrical to the midline, indicating that the accuracy of the included articles was high and there was no publication bias.

\section{Meta-analysis on residual corneal astigmatism}

Three RCTs $(17,22,23)$ analyzed the residual corneal astigmatism. Figure 8 shows the forest plot of the residual corneal astigmatism. The three articles used continuous variables to describe residual corneal astigmatism. There were 423 cases in total, including 211 cases in the Toric IOL group, and 212 cases in the non-Toric IOL group. The overall heterogeneity test was performed, and the results showed that there was heterogeneity $\left(\mathrm{Chi}^{2}=75.55\right.$, $\left.\mathrm{df}=3, \mathrm{I}^{2}=96 \%>50 \%, \mathrm{P}<0.00001\right)$. The REM analysis results suggested that the difference between two groups was not statistically significant $(Z=1.35, M D=-0.34,95 \% \mathrm{CI}$ : $-0.83,0.15, \mathrm{P}=0.18)$. Figure 9 displays the funnel diagram of residual corneal astigmatism. It can be concluded that the circles of the study were concentrated near the midline; thus, the accuracy was high, and there was no publication bias.

\section{Meta-analysis of postoperative complications}

In total, there were 3 literatures, and the postoperative complications of randomized controlled trials were analyzed. Figure 10 is the forest map of the fixed effect model of postoperative complications. Three literatures described the postoperative complications with binary variables, with a total of 429 cases, 214 cases in Toric IOL group and 215 cases in Non-toric IOL group. Postoperative complications mainly include persistent edema, pupillary block, retinal detachment and endophthalmitis. The overall heterogeneity test showed there was no heterogeneity among the studies 


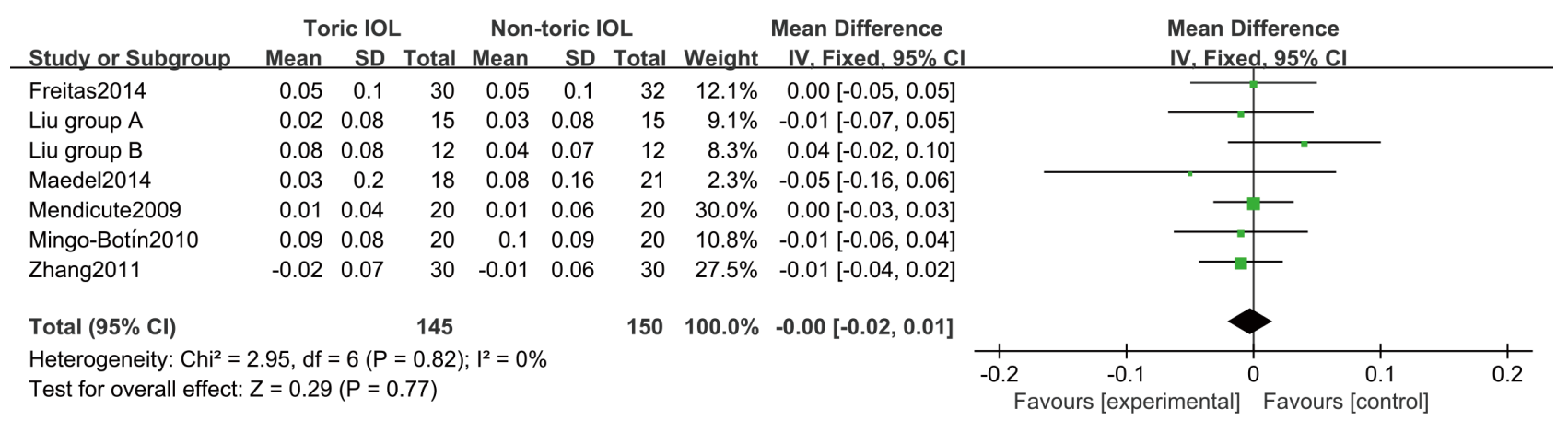

Figure 6 The forest plot of BDVA determined by the LogMAR visual acuity chart. CI, confidence interval; df, degree of freedom; IOL, intraocular lens.

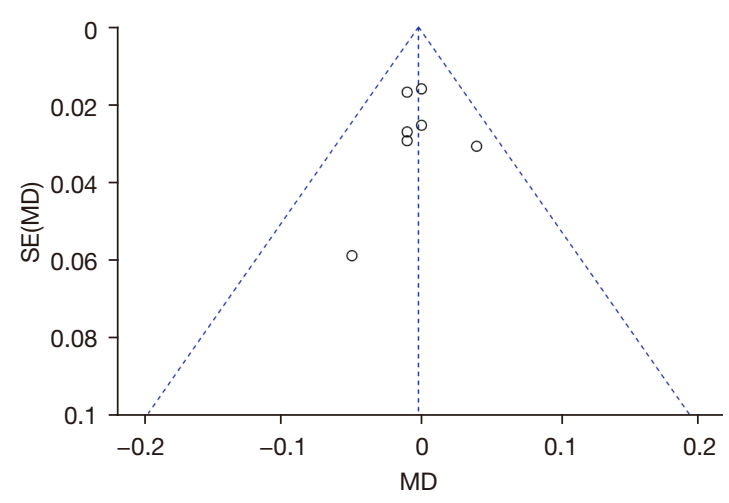

Figure 7 Funnel chart of BDVA measured by the LogMAR eye chart. MD, mean difference; SE, standard error.

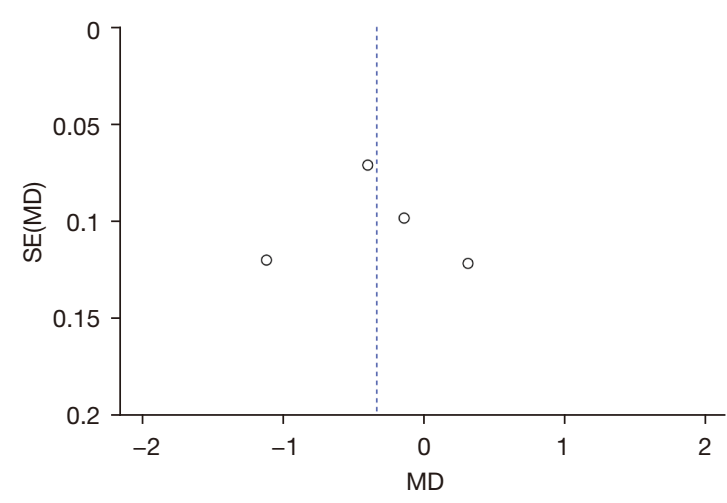

Figure 9 Funnel chart of residual corneal astigmatism. MD, mean difference; SE, standard error.

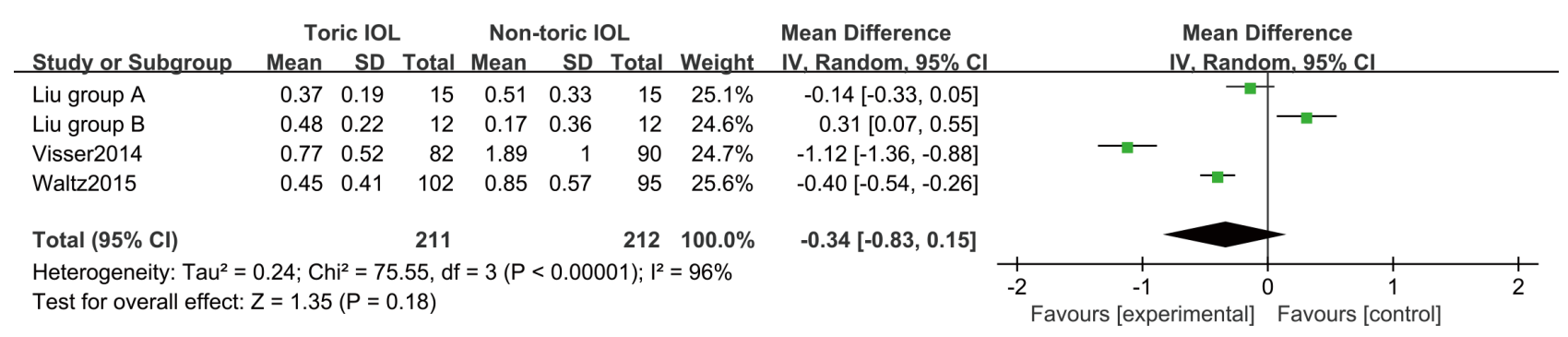

Figure 8 The forest plot of residual corneal astigmatism. CI, confidence interval; df, degree of freedom; IOL, intraocular lens.

(that $\mathrm{Chi}^{2}=0.92, \mathrm{df}=2, \mathrm{I}^{2}=0 \%, \mathrm{P}=0.63$ ). The fixed effect model was used to analyze the whole body, which showed that the difference between Toric IOL group and Non-toric IOL group was statistically significant $[Z=2.06$, OR (odds ratio) $=0.47,95 \%$ CI: $0.23,0.96, \mathrm{P}=0.04]$. Figure 11 is the funnel diagram of postoperative complications. It can be concluded that the circles of the study were concentrated near the midline; thus, the accuracy was high, and there was no publication bias.

\section{Discussion}

In recent years, cataract and refractive surgeries have gradually been combined, and an increasing number of cataract patients and doctors have begun to pursue better postoperative visual effects and smaller wounds 


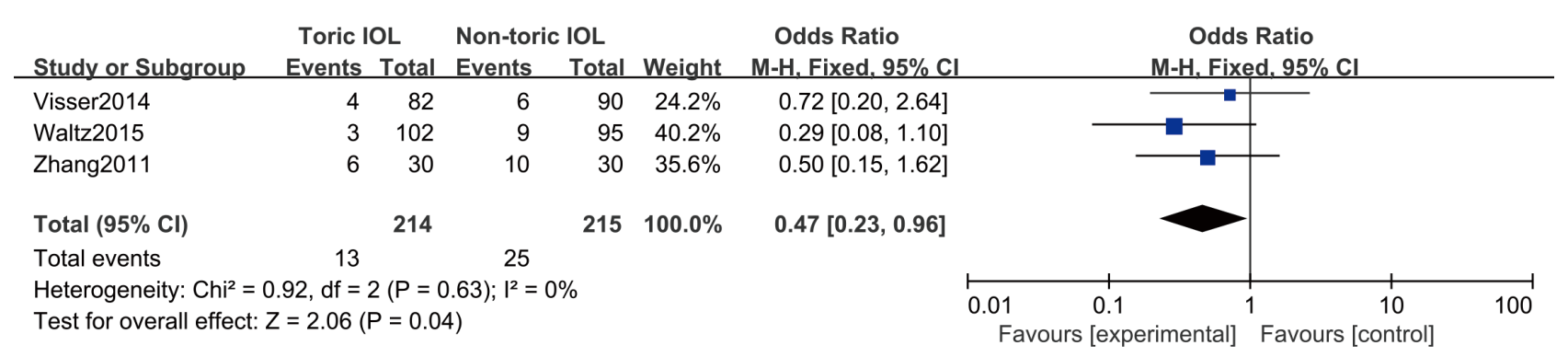

Figure 10 Forest map of the fixed effect model of postoperative complications. CI, confidence interval; df, degree of freedom; IOL, intraocular lens.

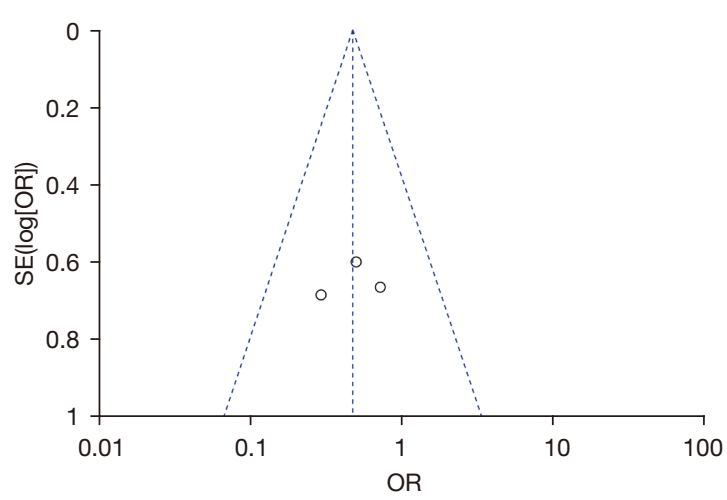

Figure 11 Funnel diagram of postoperative complications. OR, odds ratio; SE, standard error.

(25-27). Residual astigmatism after cataract surgery is the main factor affecting the visual quality of patients after cataract surgery. Therefore, the appearance of Toric IOL makes the perfect combination of IOL implantation and spherical lens correction astigmatism, thus providing a new opportunity for preoperative astigmatism (28). With the widespread application of Toric IOL, the frequency of phacoemulsification surgery in cataracts has gradually increased, and the related research has also increased. Ram et al. [2017] (29) pointed out that Toric IOL implantation had better clinical efficacy and smaller wounds than traditional lens implantation combined with contralateral clear keratotomy.

In order to further verify whether Toric IOL is better than traditional IOL in the treatment of preoperative cataract patients with corneal astigmatism, related RCTs were comprehensively searched in this study. The quality evaluation results show that there are 9 papers with grade A (75\%), 2 papers with grade B (16.67\%), and 1 paper with grade $\mathrm{C}(8.33 \%)$, which showed that the overall quality of the articles included in this study was relatively good, and the credibility was relatively high. LogMAR visual acuity chart analysis was applied to determine UDVA using REM, and showed that the Toric IOL group was statistically significant compared with the non-Toric IOL group, and the Toric IOL group had a significant therapeutic effect ( $\mathrm{Z}$ $=2.18, \mathrm{MD}=-0.05,95 \%$ CI: $-0.09,-0.00, \mathrm{P}=0.03)$. Also, analysis of residual corneal astigmatism showed that the difference between the two groups was not statistically significant, and the Toric IOL group had low residual corneal astigmatism $(\mathrm{Z}=1.35, \mathrm{MD}=-0.34,95 \% \mathrm{CI}:-0.83$, $0.15, \mathrm{P}=0.18)$. This showed that the long-term recovery of UDVA and corneal residual astigmatism in patients with Toric IOL implantation was better than that of traditional IOL implantation, which was similar to the results of Dubinsky-Pertzov et al. [2020] (30).

Many scholars use traditional IOL implantation combined with contralateral clear keratotomy to treat cataracts, and astigmatism correction is performed appropriately before the operation, which have been found to be effective (31). However, the contralateral clear keratotomy increases the difficulty and risks of the operation, and ultimately leads to the occurrence of intraoperative complications. Moreover, this surgery can also lead to poor long-term vision prediction and vision loss (32-34). Toric IOL implantation does not require invasive operations such as contralateral clear keratotomy, and has good safety and effectiveness. In this study, the efficacy index and safety index of Toric IOL group are better than those of non-toric IOL group. The contrast sensitivity of Toric IOL group in light and dark environment was higher than that before operation, and the contrast sensitivity in light and dark environment was higher. It shows that the astigmatism correction intraocular lens implantation is safe and stable in clinic and improves the visual quality. 
Phacoemulsification and astigmatism correction intraocular lens implantation for cataract patients has less postoperative reaction, fewer complications, better vision recovery, and is safe and effective. From an economic perspective, Toric IOL is more expensive than traditional IOL. However, the cost-benefit analysis shows the longterm cost of choosing Toric IOL for cataract patients with corneal astigmatism will decrease, and it will perform well in terms of long-term vision recovery, with low residual astigmatism and no additional consumption costs.

\section{Conclusions}

In this study, articles related to Toric IOL and traditional IOL implantation in the treatment of cataract patients were searched for meta-analysis, with the aim of exploring the clinical efficacy of Toric IOL implantation. The metaanalysis results confirmed that Toric IOL implantation showed obvious advantages in improving the UDVA and corneal residual astigmatism in cataract patients. Although the articles included in this study were RCTs with a good level of evidence, there were still some limitations. Firstly, this study failed to uniformly sort the complications of the included articles. Moreover, the number of studies was small, and the advantages of Toric IOL implantation for postoperative complications require further verification. In short, this study was a supplement to previous research related to Toric IOL implantation, and showed guiding significance for the clinical treatment of cataracts.

\section{Acknowledgments}

Funding: None.

\section{Footnote}

Reporting Checklist: The authors have completed the PRISMA reporting checklist. Available at https://apm. amegroups.com/article/view/10.21037/apm-21-3767/rc

Conflicts of Interest: All authors have completed the ICMJE uniform disclosure form (available at https://apm. amegroups.com/article/view/10.21037/apm-21-3767/coif). The authors have no conflicts of interest to declare.

Ethical Statement: The authors are accountable for all aspects of the work in ensuring that questions related to the accuracy or integrity of any part of the work are appropriately investigated and resolved.

Open Access Statement: This is an Open Access article distributed in accordance with the Creative Commons Attribution-NonCommercial-NoDerivs 4.0 International License (CC BY-NC-ND 4.0), which permits the noncommercial replication and distribution of the article with the strict proviso that no changes or edits are made and the original work is properly cited (including links to both the formal publication through the relevant DOI and the license). See: https://creativecommons.org/licenses/by-nc-nd/4.0/.

\section{References}

1. Vasavada V, Shastri L, Vasavada AR, et al. Visual outcomes after toric intraocular lens implantation in pediatric eyes undergoing cataract surgery. J Cataract Refract Surg 2020;46:1102-7.

2. Visser N, Berendschot TT, Bauer NJ, et al. Accuracy of toric intraocular lens implantation in cataract and refractive surgery. J Cataract Refract Surg 2011;37:1394-402.

3. Kaur M, Shaikh F, Falera R, et al. Optimizing outcomes with toric intraocular lenses. Indian J Ophthalmol 2017;65:1301-13.

4. Behshad S, Tucker J, Garg SS. Toric Intraocular Lens Alignment: Manual Versus Automated Alignment Techniques for Toric IOLs. Int Ophthalmol Clin 2016;56:71-84.

5. de Sanctis U, Eandi C, Grignolo F. Phacoemulsification and customized toric intraocular lens implantation in eyes with cataract and high astigmatism after penetrating keratoplasty. J Cataract Refract Surg 2011;37:781-5.

6. Mendicute J, Irigoyen C, Aramberri J, et al. Foldable toric intraocular lens for astigmatism correction in cataract patients. J Cataract Refract Surg 2008;34:601-7.

7. Chamberlain PD, Montes de Oca I, Shah R, et al. Preoperative Prediction of the Optimal Toric Intraocular Lens Alignment Meridian. J Refract Surg 2018;34:515-20.

8. Iovieno A, Yeung SN, Lichtinger A, et al. Cataract surgery with toric intraocular lens for correction of high corneal astigmatism. Can J Ophthalmol 2013;48:246-50.

9. Rigi M, Al-Mohtaseb Z, Weikert MP. Astigmatism Correction in Cataract Surgery: Toric Intraocular Lens Placement Versus Peripheral Corneal Relaxing Incisions. Int Ophthalmol Clin 2016;56:39-47.

10. Liu Z, Zhou R, Xu K, et al. Efficacy comparison between 
toric intraocular lens and aspheric intraocular lens plus steep-axis incision in cataract patients with low corneal astigmatism. Ann Palliat Med 2021;10:2610-9.

11. Patil MS, Nikose AS, Bharti S. Visual outcome and refractive status with monofocal toric intraocular lens implantation to correct astigmatism during cataract surgery. Indian J Ophthalmol 2020;68:3016-9.

12. He S, Chen X, Wu X, et al. Early-stage clinical outcomes and rotational stability of TECNIS toric intraocular lens implantation in cataract cases with long axial length. BMC Ophthalmol 2020;20:204.

13. Freitas GO, Boteon JE, Carvalho MJ, et al. Treatment of astigmatism during phacoemulsification. Arq Bras Oftalmol 2014;77:40-6.

14. Gangwani V, Hirnschall N, Findl O, et al. Multifocal toric intraocular lenses versus multifocal intraocular lenses combined with peripheral corneal relaxing incisions to correct moderate astigmatism. J Cataract Refract Surg 2014;40:1625-32.

15. Hirnschall N, Gangwani V, Crnej A, et al. Correction of moderate corneal astigmatism during cataract surgery: toric intraocular lens versus peripheral corneal relaxing incisions. J Cataract Refract Surg 2014;40:354-61.

16. Holland E, Lane S, Horn JD, et al. The AcrySof Toric intraocular lens in subjects with cataracts and corneal astigmatism: a randomized, subject-masked, parallelgroup, 1-year study. Ophthalmology 2010;117:2104-11.

17. Liu Z, Sha $X$, Liang $X$, et al. Toric intraocular lens vs. peripheral corneal relaxing inci- sions to correct astigmatism in eyes undergoing cataract surgery. Eye Sci 2014;29:198-203.

18. Maedel S, Hirnschall N, Chen YA, et al. Rotational performance and corneal astigmatism correction during cataract surgery: aspheric toric intraocular lens versus aspheric nontoric intraocular lens with opposite clear corneal incision. J Cataract Refract Surg 2014;40:1355-62.

19. Mendicute J, Irigoyen C, Ruiz M, et al. Toric intraocular lens versus opposite clear corneal incisions to correct astigmatism in eyes having cataract surgery. J Cataract Refract Surg 2009;35:451-8.

20. Mingo-Botín D, Muñoz-Negrete FJ, Won Kim HR, et al. Comparison of toric intraocular lenses and peripheral corneal relaxing incisions to treat astigmatism during cataract surgery. J Cataract Refract Surg 2010;36:1700-8.

21. Titiyal JS, Khatik M, Sharma N, et al. Toric intraocular lens implantation versus astigmatic keratotomy to correct astigmatism during phacoemulsification. J Cataract Refract Surg 2014;40:741-7.
22. Visser N, Beckers HJ, Bauer NJ, et al. Toric vs aspherical control intraocular lenses in patients with cataract and corneal astigmatism: a randomized clinical trial. JAMA Ophthalmol 2014;132:1462-8.

23. Waltz KL, Featherstone K, Tsai L, et al. Clinical outcomes of TECNIS toric intraocular lens implantation after cataract removal in patients with corneal astigmatism. Ophthalmology 2015;122:39-47.

24. Zhang JS, Zhao JY, Sun Q, et al. Distance vision after bilateral implantation of AcrySof toric intraocular lenses: a randomized, controlled, prospective trial. Int J Ophthalmol 2011;4:175-8.

25. Savini G, Hoffer KJ, Ducoli P. A new slant on toric intraocular lens power calculation. J Refract Surg 2013;29:348-54.

26. Alió JL, Agdeppa MC, Pongo VC, et al. Microincision cataract surgery with toric intraocular lens implantation for correcting moderate and high astigmatism: pilot study. J Cataract Refract Surg 2010;36:44-52.

27. Nanavaty MA, Lake DB, Daya SM. Outcomes of pseudophakic toric intraocular lens implantation in Keratoconic eyes with cataract. J Refract Surg 2012;28:884-9.

28. Kocová H, Vlková E, Michalcová L, et al. Incidence of cataract following implantation of a posterior-chamber phakic lens ICL (Implantable Collamer Lens) - long-term results. Cesk Slov Oftalmol Fall;73:87-93.

29. Ram J, Singh R, Gupta R, et al. Toric intraocular lens implantation in children with developmental cataract and preexisting corneal astigmatism. Acta Ophthalmol 2017;95:e95-e100.

30. Dubinsky-Pertzov B, Hecht I, Gazit I, et al. Clinical outcomes of Ankoris toric intraocular lens implantation using a computer-assisted marker system. Int Ophthalmol 2020;40:3259-67.

31. Hirnschall N, Findl O, Bayer N, et al. Sources of Error in Toric Intraocular Lens Power Calculation. J Refract Surg 2020;36:646-52.

32. Matalia H, Nandini C, Matalia J. Long-term outcome of custom toric intraocular lens for treating high astigmatism in case of cataract associated with pellucid marginal corneal degeneration. Indian J Ophthalmol 2020;68:3082-4.

33. Lesieur G. Microincision cataract surgery with implantation of a bitoric intraocular lens using an enhanced program for intraocular lens power calculation. Eur J Ophthalmol 2020;30:1308-13.

34. Nanavaty MA, Teeluck K, Bardan AS, et al. Residual 
Refractive Astigmatism following Toric Intraocular Lens Implantation without Consideration of Posterior Corneal Astigmatism during Cataract Surgery with Low Anterior Keratometric Astigmatism upto 2.5 Dioptres. Curr Eye

Cite this article as: Chi Q, Yang T, Chen Y. A systematic review and meta-analysis on intraocular lens implantation with different performances for the treatment of cataract. Ann Palliat Med 2022;11(1):260-271. doi: 10.21037/apm-21-3767
Res 2019;44:1399-406.

(English Language Editor: A. Kassem) 